\title{
Anachronistic Progress? User Notions of Lie Detection in the Juridical Field
}

\author{
BETTINA PAUL \\ UNIVERSITÄT HAMBURG \\ LARISSA FISCHER \\ RWTH AACHEN UNIVERSITY \\ TORSTEN H. VOIGT \\ RWTH AACHEN UNIVERSITY
}

\begin{abstract}
In recent years, progress in the field of lie detection has been linked to technological advances from classic polygraphs to neuroscientific brain imaging. In our empirical investigation, however, we found different notions of progress that do not comply with the popular understanding of progress as technological innovation. We follow the users of lie detection procedures in Germany in order to discern how they embrace seemingly old technologies and frame them in terms of novelty and improvement. We identify two notions of progress: one view of the polygraph in the juridical field as an instrument for procedural justice, and another view in which the device functions as a symbol of openness to improvements in the judicial system. These insights complement contemporary scholarship on lie detection by shining a critical light on the rhetoric of progress in relation to the promises of brain-based lie detection procedures. When analyzing the way polygraph tests are seen as progress, it becomes clear that the promises and hopes that are linked to this technology are of more relevance for its appraisal than its placement in time.
\end{abstract}

\section{Keywords}

technological change; progress; anachronism; technological persistence; lie detection; polygraph

\section{Introduction}

Detecting lies is a popular desire in many societal domains, from the judiciary to security to mundane daily situations. The practice of polygraph testing has been a widespread but contested

Bettina Paul, Email: bettina.paul@uni-hamburg.de

Larissa Fischer, Email: 1fischer@soziologie.rwth-aachen.de

`Torsten H. Voigt, Email: thvoigt@soziologie.rwth-aachen.de

Copyright () 2020 (Bettina Paul, Larissa Fischer, Torsten H. Voigt). Licensed under the Creative Commons Attribution Noncommercial No Derivatives (by-nc-nd). Available at estsjournal.org. 
phenomenon. Despite the controversy around lie detection, particularly its scientific reliability and validity, it is still being used in various countries around the world. Germany is a particularly interesting case in point. The use of polygraph test results in court was initially considered "unconstitutional" by the German Federal Court of Justice in a famous ruling in 1954, but was later seen as merely "not suitable" in 1998. While polygraph testing is still perceived by the broader public as being prohibited for court use, there is in fact a small group of practitioners who conduct lie detection tests as part of court proceedings. However, this practice is little known and it is hardly ever talked about in public. Unlike other countries where polygraph testing is a practice used by the police or in probation services, it is pretty much limited to the field of legal psychology in Germany. It is important to highlight that the legal situation prohibits the use of the polygraph for a confessional motivation (as it is used in, for example, the United States), and it may not be used to someone's disadvantage. Today, polygraph testing in the German court system lives a niche existence, but one that is seen to be of great potential by those who are involved.

The public perception of lie detection is largely influenced by American films in which an analogue polygraph is used. Even though this does not have much in common with current practice in German courts, it fosters the notion that it is a device of the past. The basic theories involved in lie detection practice and research have not fundamentally changed since the conceptualization of the lie detection test by William Moulton Marston in 1915 (Bunn 2012, 12223). However, technological tools to measure bodily reactions are constantly evolving: from analogue to digital polygraphs, and from there to purely automated procedures. Current examples focus on using eye tracking systems, facial thermal measurements, or the computerized analysis of facial action coding units (see Egbert and Paul 2019). These tools are mostly emerging in the field of automated security systems, but there is also a notion of progress in court procedures pushed by technological change, as can be seen in the discussion on the digitization of the law and legal procedures (see Oswald 2020).

In light of these developments the polygraph seems to be "out of joint with time," as the common use of the term "anachronism" implies (Landwehr and Winnerling 2019, 11). The concept of anachronism implies the idea of a specific chronological order of time in which technological devices have their correct place; or, as Achim Landwehr and Tobias Winnerling $(2019,11)$ put it, "Anachronism lives from the idea of a single and correct time that can serve as a benchmark for appropriate assessments."

Bruno Latour $(1993,69)$ argues that we should be critical of the archaism that moderns see in artifacts of the past. We follow Latour when analyzing the polygraph as a publicly perceived anachronism. Instead of judging whether or not the polygraph is outdated and a technology of the past, we take contemporary lie detection practices seriously and try to understand the views of the users in the field. Inspired by scholars who highlight the relevance of users in the study of

\footnotetext{
" "Lie detection" is a colloquial, non-standard term. Scientists and other experts in the field are more likely to speak of "detection of deception" or "psychophysiological significance analysis." Nevertheless, we will use the terms interchangeably because, together with the term "polygraph," they are frequently used in the juridical field, the focus of our analysis.
} 
technological change (Oudshoorn and Pinch 2003; Pinch 2009; Edgerton 1999, 2019; Weber 2019), we seek to investigate the persistence of the polygraph by following the perspectives of its users. We will discuss our insights in the context of a broader view of lie detection scholarship, adding a further facet to the collective search for explanations of its persistence. In order to do so, we investigate the public understanding of science and technology in the context of lie detection by focusing specifically on different user groups in what Arne Schirrmacher $(2008,84-88)$ describes as a "professional public." We therefore let the actors of the field shape the term "progress" in vivo. When talking to users, we learned that the polygraph was not treated as a reenactment or reinvention of an old procedure but was rather connected to the notion of progress. Confronted with the surprise of finding the polygraph framed as progress even though it is often considered an old technology or practice, we ask what users understand as progress in the field of lie detection. This question is usually not at the forefront of scholarship in the field of lie detection.

The social-scientific and historical scholarship on lie detection raises a similar question about how the persistence of the polygraph, despite its contestation, can be explained; most of this literature searches for an answer in places other than those we investigate here, and it is mainly interested in the genealogy of lie detection. Geoffrey C. Bunn $(2012,5)$, for instance, investigates how the polygraph was "constructed as a technology of truth." He also shows why it remains a vital part of the longings of law and order professionals, emphasizing the roots of criminal anthropology. He suggests that criminology is stuck in an "antagonistic circuit between the will to truth and the will to power" (Bunn 2012, 189), and argues that the dreams of the public are responsible for the pressure on law enforcement agencies to use whatever has been offered to them as technological solutions with the promise that they will be able to solve problems of crime. Bunn argues further (ibid.) that "science aims at truth, governance at spectacle." In a similar vein, Ken Alder $(2007,195)$ shows how Marston repositioned the test from science to science fiction, thereby setting free its "capacity to amplify people's fears and hopes."

John Baesler $(2018,22)$ also engages with the US perspective and analyzes polygraph use during the Cold War. He specifically focuses on the symbolic function the polygraph had for American foreign policy, and explains the device's historical persistence through the ideological credentials it borrowed from the security state (see also Segrave 2004, 48-72, 184). Another investigation of the historical persistence of polygraph application is laid out by Andrew Balmer (2018). He points to the ontological uncertainties in science that can be made explicit in relation to this development (Balmer 2018, 145-56). While all these works raise the question of the continuing use of the polygraph up to the present day, Melissa Littlefield emphasizes that one should look at the co-existence of old and new devices in the field. In her case histories on the reciprocal inspiration of science and fiction in the United States, she points to the "century-long similarities-rather than ruptures-between historical and contemporary versions of deception detectors" (Littlefield 2011, 17). What Littlefield outlines on a discursive level for the United States is something we found to be true in the field of polygraph practice in Germany as well.

Lie detection does not mirror the view of a "naive account of progress" (Edgerton 1999, $121)$, in which the classic procedures are replaced by new devices and less contested approaches. German courts rely on analogue as well as digital systems. Therefore, the concept of the order of 
time is not a relevant aspect in the assessment of field-specific problems and solutions. Rather, technological change implies the simultaneity of seemingly old and new technologies (Edgerton 1999). Like scholars of technological change, such as Latour (1993), David Edgerton (1999), Trevor Pinch (2009) and Heike Weber (2019), who highlight the fact that seemingly old technologies are often kept meaningful, we found the persisting presence of the polygraph in an environment that disapproved of it.

In our analysis, we identify two notions of progress that have emerged in the field of lie detection. One notion is progress as a solution potential, and the other relates to specific promises connected to the materiality of the technology. We argue that, taken together, these notions explain what appears to be an anachronistic progress.

This finding shows that the actual technicity of technology (Nordmann 2014) is not at the forefront when a narrative of technological progress is applied in the field of lie detection. This article seeks not only to explain how a seemingly old technology is still being used despite the objections to it, but also how and why it comes to be contextualized as progress by particular publics.

\section{User Notions of Progress: Analytical Lens and Empirical Field}

Whether technology is seen critically or euphorically, the term "progress" usually functions to signify technological innovation. Progress is seen as breaking with the past, leaving it behind in archives and museums (Latour 1993, 69); this conforms to a linear model of time that has been abandoned in historical studies, the history of technology, and other fields (see Heßler and Weber 2019, 7; Edgerton 2019, 3). In the public's view of the history of technology and the public understanding of science, though, notions such as the linear chronology of technological developments and the idea of a "technological fix" are alive and well (see Heßler and Weber 2019, 7).

This also holds true for digital technologies involved in lie detection. The theory of progress is closely linked to new technologies, which in the last decade of the 20th century were materialized by neuroscientific approaches like functional magnetic resonance imaging (fMRI) and most recently by fully automated technologies. Both the broader public discourse and the professional public view of the (neuro)science classified the polygraph as an anachronistic and questionable technology that had been challenged by newer technologies like brain imaging. These innovations came with new promises, since they were perceived to have overcome the shortcomings of the older tools (Langleben and Moriarty 2013). After 9/11, neuro-imaging solutions for lie detection were explicitly envisioned for national security interests (for critical analyses see Littlefield 2011, 118-40; Baesler 2018; Alder 2007, 264-7). Littlefield (2011, 17) calls into question what can be seen as the dominant "progressive narrative of technological advancement," in which neuroscientific procedures seem to have outperformed the polygraph. When analyzing the application of fMRI procedures in lie detection contexts, she characterizes them as "ahistoricist" $(2011,3)$, since they accept the theoretical assumptions of the polygraph test. 
Although contested, the polygraphic test procedure is widespread both in the United States and in Europe. Even though in Germany the practice has been fundamentally challenged by the Federal Constitutional Court (the highest court in Germany) since the 1950s, it has found its way into juridical practice and is occasionally used in court proceedings. ${ }^{.}$The operational context in Germany differs from how the test is utilized in most parts of the world, where the police use polygraph tests in interrogations and governmental institutions use them to assess employees and job applicants. Whereas in countries like the United States, Israel, China, Korea, Mexico, and Japan such test procedures are well established (for an overview see Vrij 2008, 295), in Europe the situation has changed considerably in recent years. Since 2001 and 2014 respectively, the Netherlands and the United Kingdom have followed the US tradition of performing a postconviction polygraph examination (PCSOT) using the polygraph test as a treatment and monitoring tool for sexual offenders on parole or probation (for recent changes see Balmer 2018; Meijer and van Koppen 2008). Even in Germany, where the federal ruling had been very strict on the admissibility of polygraph examinations in court since 1954, court practice began to change in the 1990s, allowing and even requesting polygraph tests in special cases (e.g. right of access for a parent in custody cases). Despite the fact that older lie detection procedures have gained ground in Europe in recent years, they remain a disputed practice. In Germany, polygraph testing is mainly used in the context of family court proceedings, and to a lesser extent in other legal fields, in penal or administrative cases, for example. In any case, polygraph tests are always conducted by legal psychologists. Unlike in the police practice of other countries, the use of the polygraph in Germany is dominated by the goal of disproving allegations rather than establishing guilt (Fischer et al. 2019; Paul et al. 2019).

Our perspective on lie detection in Germany turns away from the "intellectual short circuit" "of treating technology and progress as identical terms (Heßler and Weber 2019, 7). As in scientific realms concerning the history of technology, we follow the idea that old technologies continue to exist, as do hybrids and revisited or renewed versions of older devices. If one challenges the classic ways of thinking of technological development in linear terms, the concepts of "chronoference" (Landwehr and Winnerling 2019, 6ff.) or "different layers of time" (Weber 2019, 110 using Koselleck's idea of chronism for technology) can help us to understand the general polychronic nature and persistence of devices as well as the way they are perceived (see Weber 2019,112 ). As a result of recent critical understandings of time, there is a growing body of work by historians of technology that looks at the persistence of old technologies, at technology-in-use (Edgerton 1999, 2019; Hänggi 2015), and at cultures of maintenance and repair (instead of the implementation of new devices; on this point, see Graham and Thrift 2007; Russel and Vinsel 2018; Weber 2019; Möser 2010).

${ }^{5}$ In Germany, the 1st Criminal Senate of the Federal Court of Justice dealt with the admissibility of the test in 1998 and rejected the constitutional reservations that had existed since a verdict in 1954. Although the polygraph test was thus no longer subject to the previous ban on its use to test evidence, it was now considered unsuitable because it was deemed not to be scientifically sound enough.

${ }^{6}$ All translations are by the authors. 
Our argument is based on data collected as part of a larger research project on the use of lie detection in Germany, for which we interviewed users of lie detection procedures. We wanted to find out how they embraced the technology and the procedure connected with it. In this way, we were able to substantiate their belief in its utility and their expectations of the technological impact to which the lie detection literature points: "It doesn't matter whether lie detection works, so long as it provides the promise of changing society for the better" (Littlefield 2011, 10).

Our term "user" refers to people who use technology in the sense of "things," instruments, or devices (Edgerton 2019, xxvii). Users in our study are those who "use" the polygraph or fMRI in order to verify statements made by a person. The practice of these users varies in relation to the technology used, the test procedure applied, their disciplinary background, and the aim of the particular test. Our study included expert interviews with researchers in neuropsychological laboratories (NeuroSc), legal psychologists (LegPsy) and private investigators (PI/Sec), as well as users of this procedure in the judicial system (judges/attorneys). In total we conducted 38 qualitative interviews. We also analyzed court proceedings, and carried out participant observations in lie detection practice.

In order to investigate and understand users' perceptions of developments in the field, our approach was twofold. First, we inquired in what way lie detection was regarded as novel and progress by the users. Therefore, the specific user experience, their expectations and field conditions had to be taken into account to contextualize the way they use the technology. In looking for the specific reasons for its use, the problems that the technology was intended to solve, and the customs of the specific field practice (Pinch 2009, 48; see also Möser 2010), we got closer to their field-specific conceptions of progress. Here, then, the relation of time and technology (Weber 2019; Landwehr and Winnerling 2019) becomes important when highlighting old devices as used in relation to new problems.

Second, it became clear in our analysis that in their characterization of the technology and its specific practice in terms of progress, the polygraph and its new equivalents are relevant in their specific materiality, but even more so for what this materiality symbolizes. Only when the basic material quality is acknowledged can the symbolic quality be extrapolated (see Miller 2005). Material artifacts are a symbol of culture and therefore mediate an imagination. In this they not only refer to the imagination but also add something new to it (Geertz 1973, 49). With this emphasis on the twofold meaning of symbols, we can elaborate how the characterization of a polygraph symbolizes how the users perceive their environment at the present time, as well as how they would like it to be.

\section{Persistent Technology Seen as Progress}

We found differing views depending on the shared discipline of the users in contact with lie detection. The judges and attorneys of our study framed the use of the polygraph test as progress. Among the legal psychologists who actually conduct the tests, the understanding of the test varied. These two fields have their own "disciplinary cosmologies" (Roepstorff 2003, 117), and these cause a specific understanding of the legal procedures in truth verification. Although it is directed at the 
US legal context, Tal Golan's (2004a, 211-253) characterization of psychological testimony as a "science unwanted" in court from the early 20th century has some resemblances to the current situation in Germany. Interestingly, Golan emphasizes the resistance of the psychological discipline itself to the expectation that it would provide testimony in court.

Those judges and attorneys who ask for a polygraph test to be used must do so against the dominant critique of their discipline, since the test is still very much disputed and discredited by the court rulings. Their perspective is therefore marked by a belief that the polygraph test is worthwhile, despite the controversy. Here we find the most homogenous perspective of ascribing potential and progress to the practice in question, though they do see the polygraph itself as an aged device. How this recognition of the old facet of the device merges with one that speaks of progress will therefore be the focal point of our analysis.

Those legal psychologists who carry out polygraph testing within their practice of statement analysis for the court are limited to using one test procedure and one device only, mainly because only one test version applies to the kind of cases involved, but also because practice differs in its variety from research. They were trained on their devices and have used them since then. Therefore, the relevance of the procedure and device, for them, is slightly different from their psychological colleagues mentioned above. Most of the legal psychologists who once offered polygraph testing have stopped doing so. Only very few keep the whole practice going. Those who have retired take a different view of their practice, since they are looking back with more resignation than the few who still offer it.

\subsection{Problem Solving Capacity}

The central notion of progress comes from judges and attorneys who ask for polygraph testing for their cases. They consider the polygraph test to be a solution for the most difficult cases in their work. ${ }^{s}$ None of our interviewees ever took the decision to use a polygraph test lightly. They turned to it when they saw no other way to resolve a problematic case. The two main juridical fields-the penal and family law domains--had different aims and views of the test's potential. In both fields, the cases where the polygraph was used most often involved an allegation of sexual (or physical) abuse, where there were contradictory allegations and no further evidence to prove either side was giving an accurate account. The specificity of family law lies in the fact that children are involved. A solution must be found quickly, so that the children do not have to stay with a parent who may be abusing them. Accusations of sexual abuse of a child (or the partner) sometimes come up in the course of an escalating separation and a dispute about child custody. It is then a difficult task for the family judge, who carries a heavy responsibility to figure out whose statements are to be trusted and what solution would be in the best interest of the child.

\footnotetext{
- Verbal statement analysis, which is the dominant psychological procedure in the German court system, is not recognized by courts in the United States, Canada, or the United Kingdom (Pérez and Martínez 2010).

"In his social history of the polygraph, Kerry Segrave $(2004,185)$ compares the device to ancient methods of lie detection and identifies the continuing idea that it offers "a resolution to a situation."
} 
The stakes are also high in the criminal court cases. Here, conviction as a sexual offender would ruin a person's life. Once allegations are made public, people usually lose their jobs, friends, and family, since the stigma of sexual offences can hardly be washed off even if the charges turn out to be unjustified. If convicted they lose their freedom, and if not they still lose a lot. The responsibility of the judicial system is very heavy. Those responsible are faced with the difficulty of proving that somebody committed a crime, not just that somebody is not telling the truth about what happened. There may be many other reasons why people are not telling the truth, including the possibility of false confessions.

What kind of solution does the polygraph offer from the perspective of our interviewees? Family court judges say that their aim in handling family custody cases is to pacify escalated family disputes. In their view, the polygraph test offers a way toward this pacifying process. The whole test procedure includes a thorough exploration of the case led by a legal psychologist. One judge described the process of the polygraph test (which is then just a small part of the whole test procedure) as being a "catharsis" (judge 26). This "soul cleansing" process can lead to a situation where all parties are able to talk to each other again, something that was not possible before. They might have found out that the allegations were just part of an escalation process. Sometimes the exploration makes the actual use of the polygraph unnecessary, because it leads to a confession.

The court's aims are different in the penal law context, where one of the main concerns is to establish the succession of events (the "historical truth" of what happened, in the words of judge 28). For the interviewees in penal law the polygraph offered an "equality of arms" (judge 28; or "equality of chances," attorney 29) and therefore embodied procedural justice. For the witness who has made the allegations of abuse, there exists the option of a content-based statement validity analysis by a legal psychologist to verify their allegations. For the accused person there is no such instrument to verify their statement, since all they can do is deny the allegations. But denying is not the same as explaining an event, which could undergo a statement analysis (since the content analysis method scrutinizes whether there is an actual experience at the heart of the stated event). It is for this situation that the polygraph test is seen as an "instrument for the accused" (judge 28), as something equivalent to the content analysis that the witness for the prosecution can draw on.

The legal psychologists that conduct these tests voice the same view: that the polygraph is used when it is hard to prove that somebody has not done something, and so they even call it a way of proving the innocence of a person (LegPsy 08). In the interviewees' opinion, the polygraph creates a balance of options for someone to defend him/herself against false accusations. For the accused it seems to be the "last straw to cling to," as one attorney (31) expresses it. Even legal psychologists who have stopped using the polygraph procedure see the same potential for addressing the aforementioned challenge, but no socio-political change that would make its application feasible.

Wherein, exactly, then, lies the attribution of progress? We found in both legal fields of inquiry that the judges considered international developments of recent years in the direction of increasing legal protection of sexual self-determination and protection from violence to have been an improvement. At the same time, they did not think procedural law had developed accordingly 
in terms of the legal instruments available to ensure those rights. This gap was a matter of concern that confronted judges in both fields as they saw themselves.

In penal law this is a reason for associating the polygraph with future potential, since it offers a solution to what is seen as a growing gap between increasing rights and methods available to the courts to ensure those rights. This also connects with visions of the way our society is developing and its effects on the judicial system, including growing numbers of false accusations. From this perspective, the polygraph test can help by creating indices when no other option works, though only when conducted in a proper way by an experienced legal psychologist.

A penal law attorney who is more critical of the polygraph also acknowledges the gap, but sees the potential of the polygraph under future conditions when it has been improved, referring to the technology and procedure alike (attorney 29). He sees the polygraph as having been modern in the past, and having the potential to be modern again. Another aspect of the future potential to ensure a fair procedure is emphasized by a penal attorney who asks for the polygraph test for his clients (attorney 31). He points out that the police and judges generally observe bodily signs of an accused person and use them for their interrogation reports. However, the moment those same signs are measured with the help of a polygraphy, they are treated differently and deemed unacceptable. In the view of this attorney, the "subjective" police observations are "antiquated." The polygraph registrations, on the other hand, are not, since they are more correct, transparent, and precise. The attorney's criticism of this injustice of the procedure is only overshadowed by the injustice that might possibly be created through the polygraph test, because such a test is not affordable for everyone and this might cause a different form of injustice (apart from the question of voluntariness raised by Alder 2007, 261). In the field of penal law, the discussion of practitioners strongly focuses on the defense side of the application, which is very different from the way the procedure is implemented in the United Kingdom. There the polygraph test became a measure of monitoring sex offenders after their conviction, as part of a political "tough on crime" program (Balmer 2018, 147).

In family courts, the problem to which the polygraph test offers a solution differs slightly. Again, there is the confrontation of two opposing sides and accusations that have to be cleared up. In this context the polygraph practice provides an instrument to restore lost trust. One judge refers to it as a "confidence building measure" (judge 27). Attributing progress in this context is similar to the way the penal field seeks to avoid using old ways to manage problems of the future that create difficulties in their sensitive work: "I cannot try to get a grip on today's problems with methods from the last century" (judge 26). Here, the polygraph is not a method from the past. Rather, it signals future problem-solving potential. This embodies an example of chronoferences that show their "effectiveness into the future" (Landwehr and Winnerling 2019, 16).

In both legal fields, the overall certainty of its potential comes from the conviction that the polygraph procedure draws on "biofeedback" that is based on "inevitable physical reactions" (judge 28). For the proponents of the procedure the physical measurements are a "safe bank," since they cannot be manipulated or faked (judge 28). And the physical reactions measured are seen as more reliable than a content statement analysis made by a psychological court expert (which is 
currently the most used and widely accepted method of credibility assessment in German courts). The skepticism with regards to psychological content analysis is directed to the communicative basis of a procedure that is seen as inherently subjective, while the measurements of the polygraph are considered much more objective.

To summarize our findings to this point, it has become clear how the polygraph (as a token for the polygraphic test procedure) is seen as progress: it promises to solve problems that are increasingly arising in the context of and are specific to the juridical field.

\subsection{Technicity and Symbolism}

As the first notion of progress showed, it is linked to something that goes beyond the technicity of the instruments in question. But there is more to it than this. When our interviewees talked about polygraph practice, the characterization of the technology was not just symbolic. Unlike Alfred Nordmann (2014), who argues that modern technology is perceived as modern precisely because it lacks what speaks of technicity, in the case of the polygraph it is seen as something modern only because it symbolizes technicity.

The relevance of technicity comes into play when the devices are described in their material quality and its effects. This is especially noteworthy since the polygraph is part of a sociotechnical system, from which those who conduct the tests are as inseparable as those who are subject to it. Talking about the polygraph can hardly be disconnected from talking about the polygraph test, since that is its usage in the present context. ${ }^{10}$ So whenever the device itself is in focus, it is important to look at the rationale behind it. The distinction might be drawn on the basis of materiality, because "[t]he stance to materiality also remains the driving force behind humanity's attempts to transform the world in order to make it accord with beliefs as to how the world should be" (Miller 2005, 2). According to Geoffrey C. Bunn, even Marston complained that the public did not recognize that lie detection is not a machine but a test (Bunn 2012, 126).

The polygraph system exists in a multitude of material versions, in particular analogue and digital ones. The analogue systems are remnants of an earlier period, since nowadays only digital systems are being produced and sold. Still, since the materiality and functions of the analogue systems are quite durable and there are companies that offer repair services, they have their own persistency. The difference between analogue and digital versions of the polygraph is of some importance when it comes to the relevance of its technicity.

- For the neuropsychologists we interviewed, however, the measurement parameters obtained by means of polygraphy are as up-to-date today as ever but the device as such is no longer of use to them. They consider the polygraph too one-sided for research in its portable form, and even in earlier emotion research it was more useful as a modular system. Like the legal psychologists, the neuropsychologists emphasized the relevance of the test protocol over the secondary relevance of technical support for the procedure.

${ }_{10}$ Of course, the inseparability of humans and technology is a classic feature in studies of science and technology (see Latour 1993). From a more constructionist, interactionist perspective, as Pinch $(2009,47)$ nicely puts it: "No technology is an island unto itself." 
The difference manifests itself in the materiality and form of the devices. The analogue device is described as a "heavy ... box" (judge 28), so it has a quite different presence from the digital laptop version. "The device has something. There is a roll of paper going through" (judge 26). There is a high awareness of the "old, polished thing with the chrome" (judge 30). "The polygraph is just standing there the whole time and has an effect" (judge 26). Mostly the analogue materiality is at the center of the description of an effect in an optical, haptic, and functional way.

The emphasis on this haptic feature translates into a longing for an experience with persuasive power: to be able to touch it was seen as amounting to understanding the process. The analogue device is considered transparent, "mentally comprehensible" (judge 26) in its functioning, since one can follow it while its pens are writing (attorney 31). This seemingly direct translation from the bodily reaction to the pens that move on the paper leaves the impression that there is not much room for manipulation. The digital version, on the other hand, is seen as a black box that can be hacked like any other laptop (judge 26, attorney 31). This criticism of the black box polygraph fits right in with current positions on the lack of transparency in technology from movements such as "the right to repair." This perspective is contradicted by a judge who does not care what kind of polygraph is presented to him "as long as the signal comes" (judge 27). He does not think that the analogue instrument is any more transparent than the digital one, since, according to him, both have to be used by an expert. This illustrates the limits of the expertise of judges.

Legal psychologists who work with the digital version emphasize that they interpret their data by hand, therefore applying a seemingly old technique. While they emphasize the quality of the analysis by hand, they consider the digital sensors to be more practical than an analogue polygraph. This notion of practicality in the use of the devices is highly relevant. One legal psychologist who has worked with both versions is quite happy not to have to use an analogue instrument again, since working with "these old things" means a great deal of complicated work with the handling of the paper, ink, and the configuration of the sensors and pens during the process (LegPsy 12). His verdict on the analogue polygraph was that it was already "anachronistic" when the practice began in Germany.

The analogue polygraphists who use a thermal version see their device as one that postdates older versions, for example, those that use ink (LegPsy 09). Those who work with the digital ones are glad not to have to work with the impractical analogue ones (LegPsy 12). But then they tell stories about how their computerized polygraphs have become outdated (LegPsy 08). This demonstrates that the "life durance" (Weber 2019, 130) of digital devices is shorter than those of the analogue version. The latter may break down, but they can be repaired. When criticizing methods from the past, judges refer to a time before they used a supporting device in their work.

The polygraph was seen as a device with potential for improvement even by those who criticized it as being outdated. They expressed a general need for more research and had detailed visions of how the technology could be extended to include more parameters. In describing processes that characterize digital technologies, they suggested that these features should be applied in the form of the analogue device. This "innovation in the old" is nicely characterized by 
Kurt Möser (2010, 25-27) as a situation where the functional efficiency of classic technology is so convincing to the user that they prefer a modification of the old over something new.

The legal psychologists articulate the same desire to improve the polygraph (and its method). They see great potential for the improvement of the device in increasing the precision of measurements, but in their view the court rulings of 1998 have thwarted further research and modification of the test procedure (LegPsy 9 ). This shows that from their perspective the polygraph has the potential for progression, for example, in increasing the number of biosignals it can handle (or that are recorded). The multiplicity of signals that an analogue device is able to measure is already seen as a great advantage by some. Any possibility of adding further biosignals then amounts to progress, even the fMRI is scrutinized as an opportunity to add another biosignal to the verification process (LegPsy 8). On the one hand, this supports Littlefield's $(2011,142)$ claim that new technologies for lie detection are based on old theoretical principles. On the other hand, it contradicts the development Littlefield traces, namely, that the hopes for advanced technology are solely driven by new procedures such as fMRI.

The description and appraisal of the characteristics of the polygraph stand for their immediate effect in the interaction, and they work on the symbolic level. The analogue device is convincing and seen as a necessary new method. The digital version, though, is not trusted by the judges, since it doesn't seem to be transparent. A judge points out that "we [as humans] are rather analogue and can handle [the analogue] better, because this is how we operate" (judge 26). The polygraph also "signals precision, technique. It has something ... compelling." Furthermore, it signals something "down to earth," since "it functions like a clock" (judge 26).

This old device is seen as progress since it measures human arousal in a more precise way than any human can do. The polygraph is seen as a progression from the earlier, solely human judgment; which shows that it is not compared to other technologies but rather to the purely human conduct of truth verification. This shows that the attributes of "old" and "new" are flexible in their application and depend on the context, in this case on the actual comparison (see Möser 2010, 29-30). In other cases, the device is new in a sense that it has not been seen so far in this specific juridical context in Germany, and is something unfamiliar (judge 30; attorney 31).

Apart from the fact that the notion of being old does not mean that something-like the old device-is seen as outdated, "old" can be understood as a certain quality that either the machine (the old clockwork) or a human (old school) as an art of practice with certain values might inhibit. Referring to the methods of the court, the idea of "traditional tools of the trade" (judge 26) is indeed seen as outdated. In looking at those details it becomes clear why using an old machine can still be seen as progress. It speaks of the dignity and competence of the attributes of that technology (see Möser 2010, 32-33).

When they refer to newer methods such as brain imaging for lie detection purposes most of our interviewees mentioned some potential, but no current need for this technology. Legal psychologists share the view that fMRI is not necessary for the simple registration of arousal, which

"Edgerton's concept of "creole technologies" also points out how western-centric attributions of "old" and "outdated" are, when one should rather recognize the global user-nature of technology (2019, xxiv, 43-45). 
is all they need. Therefore, they emphasize that they get no added value from the new device. One judge even felt that the polygraph poses the danger that it might pave the way for the brain scan to enter the court system, since new technological solutions have been allowed into the statement analysis court system (judge 27). This judge viewed brain scans not as an improvement but rather as Orwellian technology. This is because the feature of human decision making seems to be eliminated in that process.

Compared to other technologies the polygraph test embodies a technique that still needs human decisions. It is thus different from fully automated artificial intelligence. This points to a central issue in the discussion surrounding the polygraph. One common concern is that using the polygraph would transfer the credibility assessment of testimonials from the judge to a machine. Some judges and attorneys (judge 28, attorney 31 ) articulate this, but the legal psychologists go further in thinking the major reason for the courts' disapproval of the polygraph is that judges are afraid to lose their jobs. Looking at the procedure more closely, one can see that it needs a psychologist to develop a test. The polygraph is only a supporting device. The meta-narrative of machines taking over the judges' tasks tends to overlook this. We also found support for the polygraph as an argument for the value of the judges' work. Since a machine might not tell the judge what they want to hear, it does respect the independence of the judge even more than when humans are involved in the assessment. In an analogy of the polygraph and machine-learning systems, Marion Oswald (2020, 228) emphasizes the concern that in both cases human judgment should not be replaced by machines in the legal system.

All judges and lawyers who were engaged in the practice of using the polygraph shared the notion that the judicial apparatus in Germany is genuinely conservative and averse to innovation. New methods, technological solutions, or major changes in practice are met with skepticism. For German court practice the polygraph is an uncommon technical device, therefore they consider it to be "new" (attorney 31), "complicated and new" (31), "unfamiliar" (judge 30). Interestingly, in the eyes of the German court this "newness" does not conflict with the analogue polygraph being associated with old US movies or CIA interrogations. They consequently expressed the need for openness to new methods that are unfamiliar in the field. This is accompanied by a vision of technological progress in the field: one day, lie detection tests will be so valid and reliable that the techno-skeptical legal system will no longer be able to refuse them.

The polygraph becomes a symbol for progress in the way the term was originally used and perceived. The term comes from the French progrès in the 16th century, when it was used to symbolize scientific-technological developments. This modern connotation indicated that the world is not God-given but changeable (Hänggi 2015, 21). This notion changes when Immanuel Kant describes Fortschritt (progress) as a collective imperative of improvement. Drawing on the spirit of the French Revolution, Kant saw it as a moral (and theoretical) obligation that Fortschritt should become a reality (Koselleck 1975, 384). In Kant's version, the open temporal aspect that the term acquired when it was stripped of its religious connotations in modernity was transformed into a political one. He asked for a moral imperative. Moving to a better future should not mean leaving the future open, drawing on the term only as a call for an ongoing but never finished improvement. It had to become reality. This is reflected in the use of the term by our juridical 
interviewees. From their disciplinary cosmology, it reflects on the specific culture of the legal system in Germany. It was seen as embodying structurally conditioned obedience toward authorities, sticking to the old and not daring anything new. Because of this, our interviewees were rather pessimistic about the future of a broader implementation of the polygraph method. This aversion against novelties, especially a form of techno-skepticism, was not just ascribed to the judiciary but also seen as a general feature of German culture. This narrative seems to be in sharp contrast to the "worldview of technology" that John Baesler $(2018,15)$ sees in the United States and considers as the explanation of how the polygraph remains a persistent tool despite its contestation.

To summarize, the legal experts who are convinced of the value of the polygraph describe the device itself as old with a potential for improvement. The practice for which the device stands also signals novelty, as nothing comparable is currently established. The polygraph in its material composition and as a symbolic reference for the field of practice is forward-looking: it appears transparent and symbolizes the breaking of new ground, thus embodying progress.

\section{Conclusion}

The polygraph test is a highly contested procedure in Germany. Our interviewees perceived the criticisms directed at the polygraph as "hostility towards technology" (judge 28). The judges, in particular, have to defend their practice of using a polygraph that they consider to be progressive. When on the flipside the media approach the juridical field to portray polygraphic practice, they highlight the iconic machine and thereby embrace the epitome of anachronism.

By focusing on the persistence of a technology instead of centering on technological inventions, as suggested by Edgerton $(2019,209)$, we have extrapolated user notions of progress in the juridical field. First, we showed how the polygraph is seen as progress in terms of its problemsolving potential for the juridical field, as something that can be held up against e.g. new procedural law challenges. The current buzzword "innovation" only stands for renewal. It does not carry the pathos of world improvement as the term "progress" does. This is why progress fits so well with what the polygraph promises-a solution to problems that seem to be growing and on which legal psychologists and judges have to make decisions that have major consequences.

Second, the polygraph embodies progress as it promises transparency through its technicity. It works as a symbolic reference for the renewal of an old system and openness to new procedures like the polygraph test. The device itself symbolizes newness because it and the technicity it stands for is an unfamiliar procedure in the German court system. Even though those two understandings challenge traditional, linear views of progress, users sometimes emphasize such a linear chronology. They do so when they stress not using methods from the past to deal with future problems. They have the explicit vision of a technological solution that will ultimately be so reliable and scientifically accurate that it will not be questioned by the legal system in Germany.

The label "anachronism" does not seem to capture the developments in lie detection. The polygraph in itself is a system of different devices incorporated into a single one (sensors, writing systems, etc.). Each of these parts can be replaced by other versions, and each of them can be new 
or old depending on where one stands to judge this. Therefore, it does not seem useful to use "anachronism" in terms of a "falling out of time," -not just in conceptual terms (see Landwehr and Winnerling 2019) but also in the way it shows itself in the juridical field. The assumption that there is a strict chronology to which a device can be assigned is even thwarted by the field. There are judges who are not even aware that there are different versions of the polygraph.

The technology is progress through its technicity. Using a polygraph, then, is already progress compared to not using technological support. Beyond the technicity it is the polygraph's specific feature of visualizing physiological reactions, on paper and in near real time, that makes it convincing. A mechanically produced piece of visuality can be treated in various ways as evidence in court, from being just illustrative evidence to being seen as a silent witness on its own behalf, as Golan (2004b) shows in the case of US courts. But there is a similar divide of evidence that is seen as being of material versus human origin and a similar resistance of the court when it comes to acknowledging new forms of evidence. The polygraph test in Germany, even though producing material and visual results, is classified as part of an expert testimony and cannot be treated as independent evidence. The judges or psychologists of our study, when talking about their desires, were mixed in their views on whether the polygraph test should be accepted as an independent means of proof. At the same time, they were coherent in expressing a wish for a technological support procedure that convinces all those whose skepticism is currently slowing down the practice of credibility assessments.

To understand where and why something is seen as progress, then, has to take into account the specific reference point involved. Sometimes this applies to a common notion of linearity, and sometimes it does not because the reference point is within the inner logic of the field. That a device is placed in "the 'wrong' spatio-temporal place" (Landwehr and Winnerling 2019, 14), then, does not seem to be a fitting description. Rather, the idea of seeing different corresponding layers of time helps us to understand perspectives on the devices. Landwehr and Winnerling, in their concept of chronoferences, suggest that we can differentiate in terms of the way something is apparently "wrongly placed in time." This way one can analyze if a device is predated in artificially distancing it from one's temporal context (what they call prochorism, 2019, 15) or if it rather artificially brings the past closer to the present in an idealizing, nostalgic way (parachronism, 2019, 16). This is not the only apparent contradiction that confronts us within the chronoferences of the field. While the users view the polygraph as progress, they apply a classic progressionist view to the technological development, thereby hoping for greater acceptance through further developments.

Our close examination of the German judicial system has shown that users' views are far from being simply progressionist. With both key notions of progress in the polygraphic field, in terms of procedural potential and of material promises, the placement in time varies. Sometimes it is closer to the future, then again closer to the present, and even when it is pushed into the past it still works in the sense of progression. There is no relevant chronology here, so there is no wrong placement in time. What it comes down to is the perceived problem solving potential of the polygraph test for challenges that are anticipated to be of growing relevance in the future. 
In the end, we can state with Edgerton that "a use-based history will do much more than disturb our tidy timelines of progress" (Edgerton 2019, xii). It also allows us to understand the rationales in a field that is in need of solutions to serious questions facing it today and which are likely to grow in importance. The concept of progress then refers to the foremost non-technical category, namely the bettering of life. The polygraph as technology serves as a mediator, and is only a means to an end, no matter what layer of time it originates in. These insights complement the work that already exists in scholarship on lie detection. We have specified the "lores, desires, hopes and dreams" (Littlefield 2011, 9) of the current practitioners in the field in Germany. We have shown that the continuing attractiveness of the classic lie detection methods, despite the fact that they have been extensively scientifically discredited, is reflected in a way that goes beyond the mere self-referential stabilization of the device in its "ability to compel belief," as Alder states (2007, 195). Littlefield rightly claims that the early use of polygraph as well as newer brain-based approaches both convey "appeals to progress and benevolence" $(2011,3)$. Progress, then, is both the promise and the hope that practitioners connect to the use of lie detection technologies. The case of Germany, with its unique niche practice that is not found in penal law enforcement, is particularly interesting because it demonstrates the added value of considering the actual practitioners working in the field, since they have introduced a new perspective on the meaning of progress.

Our example has shown that independently of their timeline of development and implementation, it is the actual experience of practitioners that holds a technology and its use to be of value. The persistence of a technology can therefore be linked to the mundane needs of practice fields like that of the judiciary. The search and longing for a solution are responsible for what is seen as progress. As long as technologically supported procedures such as the polygraph test "provide the promise of changing society for the better" (Littlefield 2011, 10), they embody this spirit of progress.

\section{Declaration of conflicting interests}

The authors declare no potential conflicts of interest with respect to the research, authorship and/or publication of this article.

\section{Funding}

The research was supported by the German Research Foundation (grant number 320725678).

\section{Author Biographies}

Bettina Paul is a senior researcher at the Universität Hamburg, Germany, where she teaches in the international criminology master's program. In her postdoctoral work she ethnographically investigates how socially effective concepts of technicity develop. She currently explores how the consistency, omnipresence, and uniformity of the lie detector image in Germany can be explained. 
Larissa Fischer is a research fellow at the Institute of Sociology at RWTH Aachen University, Germany. Her research and teaching interests include the sociology of knowledge, science and technology studies, and visual culture(s). Since 2017, she has been working on her Ph.D. on the cultural implications of lie detection procedures in Germany. She is also interested in developments in the fields of neuroscience.

Torsten H. Voigt is a professor of sociology and the chair of the technology and diversity program at RWTH Aachen University, Germany. His research interests lie at the interface of science and technology studies, medical sociology, the sociology of social problems and control, race, and ethnicity, and social theory. He is particularly interested in how biotechnological innovations shape and are influenced by societal norms and values.

\section{Acknowledgements}

We thank the anonymous reviewers as well as Daniel Lee Kleinman and Katie Vann for instructive criticism of an earlier version of this article. We also express our gratitude to Gerard Holden who copy-edited the text.

\section{References}

Alder, Ken. 2007. The Lie Detectors: The History of an American Obsession. New York, NY: Free Press.

Baesler, John P. 2018. Clearer Than Truth: The Polygraph and the American Cold War. Amherst, MA \& Boston, MA: University of Massachusetts Press.

Balmer, Andrew. 2018. Lie Detection and the Law: Torture, Technology and Truth. Abingdon: Routledge.

Bunn, Geoffrey C. 2012. The Truth Machine: A Social History of the Lie Detector. Baltimore, MD: John Hopkins University Press.

Edgerton, David. 1999. "From Innovation to Use: Ten Eclectic Theses on the Historiography of Technology." History and Technology 16 (2): 111-36. https://doi.org/10.1080/0734151 9908581961.

Edgerton, David. 2019. The Shock of the Old: Technology and Global History since 1900. London: Profile Books.

Egbert, Simon, and Bettina Paul. 2019: "Preemptive 'Screening for Malintent': The Future Attribute Screening Technology (FAST) as Double Future Device." Futures 109: 108-16. https:// doi.org/10.1016/j.futures.2018.04.003.

Fischer, Larissa, Bettina Paul, and Torsten H. Voigt. 2020. "Wahrheit unter dem Vergrößerungsglas. Vorstellungen von Subjekt und Technik in der Rechtsprechung zur 
Polygraphie." Zeitschrift für Soziologie 48 (5-6): 418-34. https://doi.org/10.1515/zfsoz2019-0029.

Geertz, Clifford. 1973. The Interpretation of Cultures: Selected Essays. New York, NY: Basic Books.

Golan, Tal. 2004a. Laws of Men and Laws of Nature: The History of Scientific Expert Testimony in England and America. Cambridge, MA \& London: Harvard University Press.

Golan, Tal. 2004b. "The Emergence of the Silent Witness: The Legal and Medical Reception of XRays in the USA." Social Studies of Science 34 (4): 469-99. https:// doi.org/10.1177/030 6312704045705.

Graham, Stephen, and Nigel Thrift. 2007. "Out of Order: Understanding Repair and Maintenance." Theory, Culture \& Society 24 (3): 1-25. https: / / doi.org/10.1177/ 0263276407075954.

Hänggi, Marcel. 2015. Fortschrittsgeschichten: Für einen guten Umgang mit Technik. Frankfurt am Main: Fischer.

Heßler, Martina, and Heike Weber. 2019. "Provokationen der Technikgeschichte. Eine Einleitung." In Provokationen der Technikgeschichte, edited by Martina Heßler and Heike Weber, 1-34. Paderborn: Ferdinand Schöningh.

Koselleck, Reinhart. 1975. "Fortschritt." In Geschichtliche Grundbegriffe. Historisches Lexikon zur politisch-sozialen Sprache in Deutschland, Band 2, edited by Reinhart Koselleck, Werner Conze, and Otto Brunner, 351-423. Stuttgart: Klett Cotta.

Landwehr, Achim, and Tobias Winnerling. 2019. "Chronisms: On the Past and Future of the Relation of Times." Rethinking History 23 (4): 435-55. https: / / doi.org/10.1080 / 13642529.20 19.1677294.

Langleben, Daniel D., and Jane Campbell Moriarty. 2013. “Using Brain Imaging for Lie Detection: Where Science, Law, and Policy Collide." Psychology, Public Policy, and Law 19 (2): 222-34. https:/ / doi.org/10.1037/a0028841.

Latour, Bruno. 1993. We Have Never Been Modern. Cambridge: Harvard University Press.

Littlefield, Melissa M. 2011. The Lying Brain: Lie Detection in Science and Science Fiction. Ann Arbor, MI: University of Michigan Press.

Meijer, Ewout H., and Peter J. van Koppen. 2008. "Lie Detectors and the Law: The Use of the Polygraph in Europe." In Psychology and Law: Bridging the Gap, edited by D. Canter and R. Žukauskiene 31-50. Farnham \& Burlington, VT: Ashgate.

Miller, Daniel. 2005. "Materiality: An Introduction." In Materiality, edited by Daniel Miller, 1-59. Durham, NC \& London: Duke University Press.

Möser, Kurt. 2010. "Fortdauer und Wiederkehr des Alten in der Technik." In Techniknostalgie und Retrotechnologie, edited by Kurt Möser and Andreas Böhn, 17-40. Karlsruhe: KIT Scientific Publishing.

Nordmann, Alfred. 2014. "Sanfte Technik: Vom Mythos der Maschine zum Mythos nichtmaschineller Maschinen." In Zur Philosophie informeller Technisierung, edited by Andreas Kaminski and Andreas Gelhard, 21-40. Darmstadt: Wissenschaftliche Buchgesellschaft.

Oswald, Marion. 2020. "Technologies in the twilight zone: early lie detectors, machine learning and reformist legal realism." International Review of Law, Computers \& Technology 34 (2): 214-31. https:// doi.org/10.1080/13600869.2020.1733758. 
Oudshoorn, Nelly, and Trevor Pinch, eds. 2003. How Users Matter: The Co-Construction of Users and Technologies. Inside Technology. Cambridge, MA: MIT Press.

Paul, Bettina, Larissa Fischer, and Torsten H. Voigt. 2019. "Wahrheit detektieren: Polygrafische Praxis zwischen Technikskepsis und Maschinenglauben im Kontext der Justiz." Mittelweg 3628 (5): 84-109.

Pérez, Mercedes Novo, and María Dolores Seijo Martínez. 2010. “Judicial Judgement-Making and Legal Criteria of Testimonial Credibility." The European Journal of Psychology Applied to Legal Context 2 (2): 91-115.

Pinch, Trevor J. 2009. "The Social Construction of Technology (SCOT): The Old, the New, and the Nonhuman." In Material Culture and Technology in Everyday Life. Ethnographic Approaches, edited by Phillip Vannini, 45-58. New York, NY, Washington, DC \& Bern: Peter Lang.

Roepstorff, Andreas. 2003. "Clashing Cosmologies: Contrasting Knowledge in the Greenlandic Fishery." In Imagining Nature. Practices of Cosmology and Identity, edited by Nils Bubandt, Kalevi Kull, and Andreas Roepstorff, 117-42. Aarhus: Aarhus University Press.

Russell, Andrew L., and Lee Vinsel. 2018. "After Innovation, Turn to Maintenance." Technology and Culture 59 (1): 1-25. https:/ / doi.org/10.1353/tech.2018.0004.

Schirrmacher, Arne. 2008. "Nach der Popularisierung: Zur Relation von Wissenschaft und Öffentlichkeit." Geschichte und Gesellschaft 34 (1): 73-95. https:/ / doi.org/10.13109/ gege.20 08.34.1.73.

Segrave, Kerry. 2004. Lie Detectors: A Social History. Jefferson \& London: McFarland \& Company. Vrij, Albert. 2008. Detecting Lies and Deceit: Pitfalls and Opportunities. Chichester: John Wiley \& Sons. Weber, Heike. 2019. "Zeitschichten des Technischen: Zum Momentum, Alter(n) und Verschwinden von Technik." In Provokationen der Technikgeschichte, edited by Martina Heßler and Heike Weber, 107-50. Paderborn: Ferdinand Schöningh. 